\title{
Structure-Activity Relationship and Bioactivity Studies of Neurotrophic trans-Banglene
}

\author{
Khyati Gohil,`M. Zain H. Kazmi, Florence J. Williams*^ \\ ${ }^{\diamond}$ Department of Chemistry, University of Iowa, Iowa City, IA, USA 52246 \\ - Department of Chemistry, University of Alberta, Edmonton, AB, Canada T6G 2G2 \\ KEYWORDS neurotrophic, bioactive natural product, TrkA signaling, NGF signaling, structure-activity relationship
}

\begin{abstract}
Neurotrophic small molecule natural products are functional analogs of signaling proteins called neurotrophins, which cause a pro-growth, pro-survival, or pro-differentiation response in neuronal cells. While these phenotypic responses are desirable to combat neurodegenerative disease progression, the pharmacokinetic properties of neurotrophins present challenges to their administration. Therefore, neurotrophic small molecules such as the cis- and trans-banglenes offer attractive alternatives. We describe the synthesis and testing of banglene derivatives and establish a structure-activity response for the banglene family. We demonstrate that (-) trans-banglene is the primarily active enantiomer, and that select modifications on the cyclohexene ring of trans-banglene do not significantly impair its bioactivity. Finally, we demonstrate that $(-)$ trans-banglene potentiation of NGFinduced neuritogenesis is unaffected by the presence of these Erk1/2, Akt and Pkc inhibitors. Our structure-activity results also suggest that (-) trans-banglene neurotrophic activity and its potentiation of NGF activity might be distinct unassociated processes.
\end{abstract}

\section{INTRODUCTION}

Neurodegenerative diseases, which include Alzheimer's and Parkinson's disease, are characterized by the progressive loss of neuronal function, degeneration of neuronal structure, and decrease in brain mass. ${ }^{1}$ Despite an imminent societal need, neurodegenerative diseases have been resistant to effective therapeutic development to date. As an example, the clinical trial failure rate for new drugs has exceeded $90 \%$ over the past two decades and no current treatment for Alzheimer's disease extends life span. ${ }^{2}$ This situation stresses a need for a diverse approach in identifying therapeutic targets.

Our lab has been intrigued by the potential of neurotrophic small molecules in this medicinal area. Neurotrophic molecules are functional analogs of natural signaling proteins called neurotrophins [e.g. nerve growth factor (NGF)], which trigger proliferation, differentiation, growth, and/or regeneration in neurons or neuronal progenitor cells. ${ }^{4}$ Neurotrophin proteins have been demonstrated to increase neuron cell resistance to the cytotoxic activity of amyloid Beta $(A \beta)$ and tau, ${ }^{5,6}$ to increase neurogeneration, ${ }^{7}$ and to improve memory and learning in animal models of neurodegenerative diseases. ${ }^{8}$ However, neurotrophin proteins have short half-lives in blood and serum, and do not cross the blood-brain barrier (BBB), ${ }^{9}$ presenting significant challenges to administration. Small molecules which trigger similar phenotypic responses could address these pharmacokinetic limitations while providing similar therapeutic impact. Such molecules also constitute unique biochemical tools to modulate neurotrophic responses.

One set of neurotrophic molecules of interest are the cisand trans- banglenes ( $\boldsymbol{c}$-BG and $\boldsymbol{t}$-BG; $\boldsymbol{t}$-BG shown in Figure 1b). These phenylbutenoid dimers are isolated from the medicinal ginger Zingiber purpureum, also called Zingiber cas- sumunar. ${ }^{11}$ Cis- and trans-banglenes exhibit neurotrophic activity in primary rat neurons and neurogenic activity in neurodegenerative mouse models. They have been shown to be orally bioavailable in mice and in humans, and to cross the blood-brain barrier in mouse studies. ${ }^{12}$

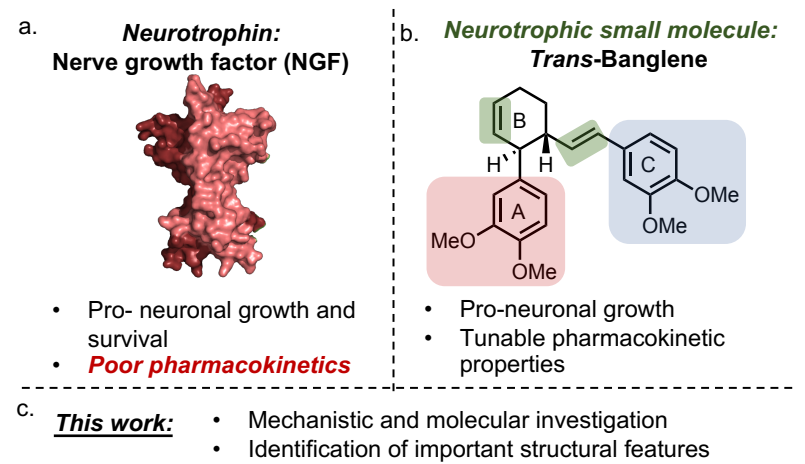

Figure 1. Methods for modulating neurotrophic responses (a) Structure (PDB: 4EAX) and properties of nerve growth factor (NGF) ${ }^{10}$ a neurotrophin protein (b) Trans-banglene structure with regions of modification targeted for structure-activity relationship studies. Cis-banglene is named for the cis relationship of the B ring substituents. (c) Highlights of the present work.

Safety profiling of extracts of Zingiber purpureum demonstrated no-adverse effects to human subjects taking 850 $\mathrm{mg}$ /day for four weeks, which corresponds to $50 \mathrm{mg}$ of cisand trans-banglene. ${ }^{13}$ In addition, cis and trans-banglene are readily accessible synthetically. ${ }^{11,14}$

Despite demonstrated bioactivity, bioavailability and safety data, there are significant gaps in mechanistic and molecular understanding of banglene activity. 
a.

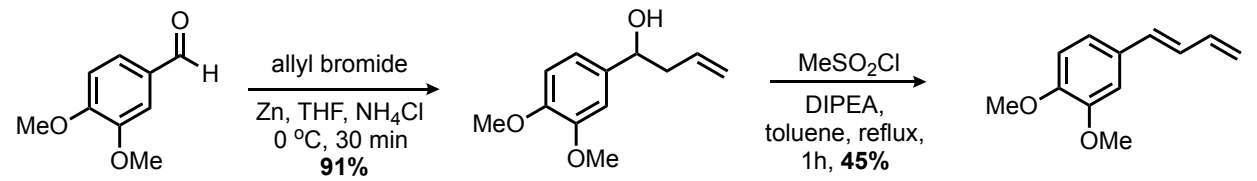

1a

2a

3a<smiles>COc1ccc(/C=C/[C@H]2CCC=C[C@H]2c2ccc(OC)c(OC)c2)cc1/C=C/c1ccc(OC)c(OC)c1</smiles>

b.

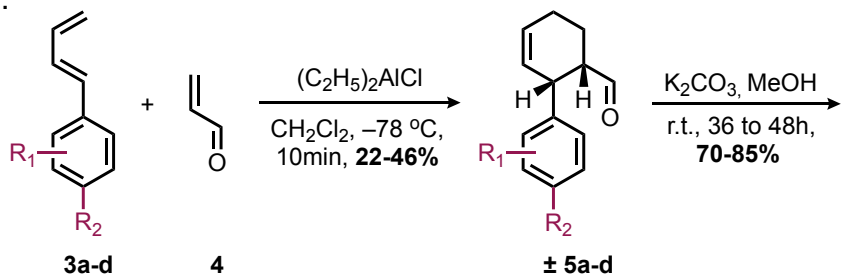<smiles>[R]c1ccc([C@@H]2C=CCC[C@@]2(C=[R])C=O)cc1</smiles><smiles></smiles>

$\pm 6 a-d$

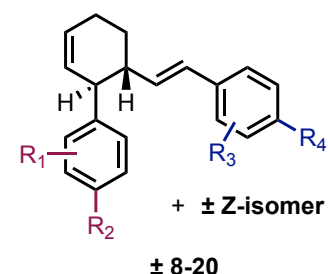<smiles>[R]c1ccc(/C=C/[C@@]2([CH]c3ccc(OC)c(OC)c3)[CH]C=CCC2)cc1</smiles><smiles>[R3]c1ccc(/C=C\C23C=CCCC2C(c2ccc(OC)c(OC)c2)C3)c([R])c1[R]</smiles><smiles>[R]c1ccc([C@H]2C=CCC[C@@]2(/C=C/c2ccc(OC)c(OC)c2)CC)cc1[R]</smiles>

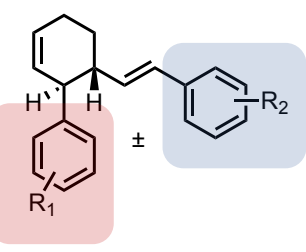

$20 \mathrm{R}_{1}, \mathrm{R}_{2}=m-\mathrm{OMe}$, $21 \mathrm{R}_{1}, \mathrm{R}_{2}=p-\mathrm{OMe}$

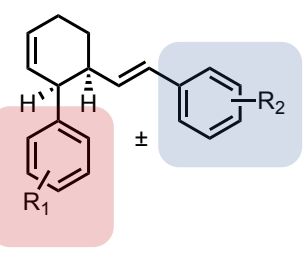

$22 \mathrm{R}_{1}, \mathrm{R}_{2}=m-\mathrm{OMe}$ $23 \mathrm{R}_{1}, \mathrm{R}_{2}=p-\mathrm{OMe}$

$$
\begin{aligned}
& 9 \mathrm{R}=m-\mathrm{OMe} \\
& 10 \mathrm{R}=p-\mathrm{OMe} \\
& 11 \mathrm{R}=o-\mathrm{Me} \\
& 12 \mathrm{R}=o-\mathrm{Br}
\end{aligned}
$$<smiles>COc1ccc(CC[C@@H]2CCCC[C@H]2c2ccc(OC)c(OC)c2)cc1OC</smiles>

$\pm 24$
$13 \mathrm{R}_{1}=\mathrm{H}, \mathrm{R}_{2}=\mathrm{OMe}, \mathrm{R}_{3}=\mathrm{OM}$

$14 \mathrm{R}_{1}=\mathrm{H}, \mathrm{R}_{2}=\mathrm{OMe}, \mathrm{R}_{3}=\mathrm{H}$

$16 R_{1}=M, R_{2}=H, R_{3}=H$
$17 \mathrm{R}_{1}=\mathrm{H}, \mathrm{R}_{2}=\mathrm{OMe}$
$18 \mathrm{R}_{1}=\mathrm{OMe}, \mathrm{R}_{2}=\mathrm{H}$
$19 \mathrm{R}_{1}=\mathrm{OH}, \mathrm{R}_{2}=\mathrm{OM}$
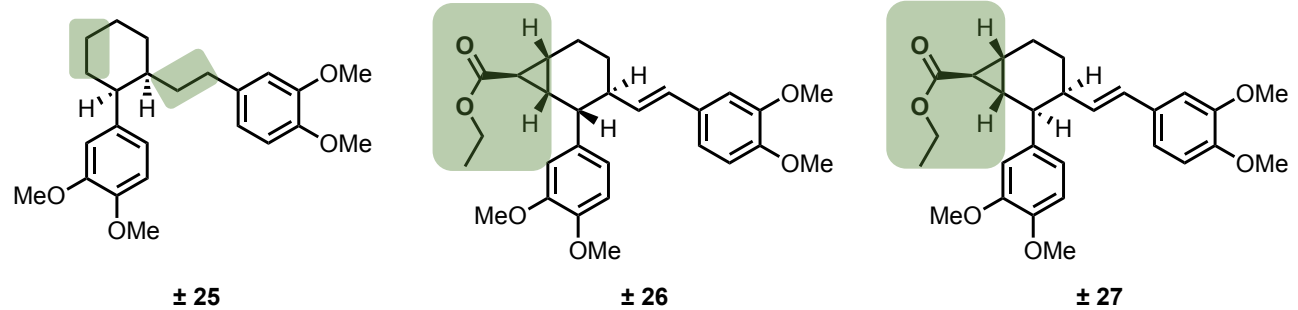

Figure 2. Synthesis and structures of various Banglene derivatives (a) Synthetic route to access $\boldsymbol{t}$-BG and $\boldsymbol{c}$-BG through Diels-Alder dimerization. (b) Synthetic route to access derivatives with distinct A and C ring modifications using a Wittig olefination. (c) Banglene derivatives for investigation of their neurotrophic activity.

Structural features responsible for the neurotrophic activity of the banglenes have not yet been identified and neurotrophic testing has been performed exclusively with racemic mixtures. Further, it is unclear whether banglenes intercept NGF-related signal transduction pathways or if they operate through distinct mechanisms.

This work describes preliminary structure-neurotrophic activity relationship investigations for trans-banglene, including the testing of all stereoisomers. Additionally, a series of PC-
12 neuritogenesis tests explore the impact of trans-banglene on canonical neurotrophic signaling pathways.

\section{RESULTS AND DISCUSSION}

\section{Chemical Synthesis}

Cis- and trans-banglene ( $\boldsymbol{c}$-BG and $\boldsymbol{t}$-BG) were synthesized using a reported Diels-Alder dimerization from diene 3 (Figure 2a). ${ }^{11}$ Diene $\mathbf{3}$ was accessed from 3,4dimethoxybenzaldehyde 1 using zinc-mediated allylation followed by a mesylation and elimination of the resulting ben- 
zylic alcohol. The Diels-Alder cycloaddition provided a mixture of cis- and trans-banglene with no apparent endo/exo selectivity, as previously reported. ${ }^{11}$ All stereoisomers were separated using reverse-phase HPLC. This strategy was also used to generate derivatives with identical substitution patterns on the $\mathrm{A}$ and $\mathrm{C}$ rings (Figure 2c, 20-23).

Twelve more derivatives of the banglene scaffold were generated using a Wittig reaction with cyclohexene aldehydes 5ad (Figure 2b), allowing for differential substitution on the two aromatic rings (A and $\mathrm{C}$ ) of the banglene structure. Interestingly, Horner-Wadsworth-Emmons reactions proved unsuccessful with trans-aldehyde 6a, despite success with ciscompound $\mathbf{5 a}$, which is consistent with previous reporting by Lim and coworkers. ${ }^{13}$

Further derivatization of the cyclohexene ring of transbanglene was achieved through a palladium-catalyzed hydrogenation or a rhodium-catalyzed cyclopropanation, generating compounds 24-27 (see Supporting Information for details). The enantiomers of compounds 8-17, and $\mathbf{2 3}$ were separated by chiral chromatography.

\section{PC 12 Neuritogenesis Assays}

Cis-banglene was observed to crystallize and precipitate out of cell media at $30 \mu \mu \mathrm{M}$ concentration (DMEM+5\%HS+5\%FBS, see Supporting Info, Figure SI1). Therefore, cell assay studies focused on trans-banglene, which showed no solubility challenges at $30 \mu \mathrm{M}$. a.

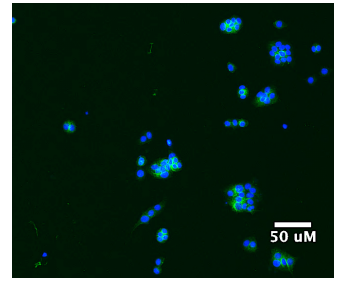

DMSO

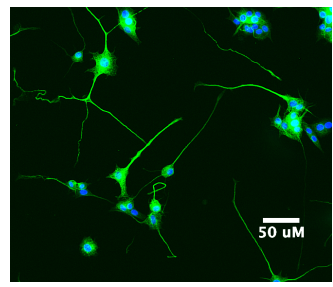

NGF $10 \mathrm{ng} / \mathrm{mL}$

b.

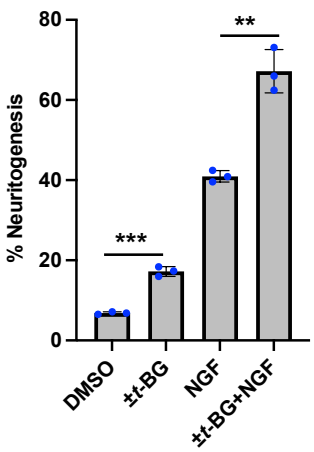

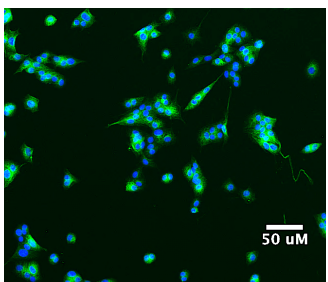

$\pm t$-BG $(30 \mu \mathrm{M})$

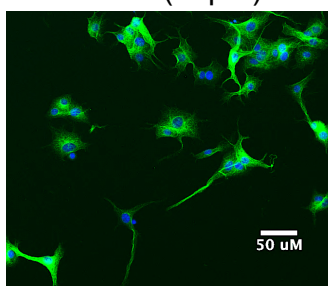

$\pm t-\mathrm{BG}+\mathrm{NGF}$

C.

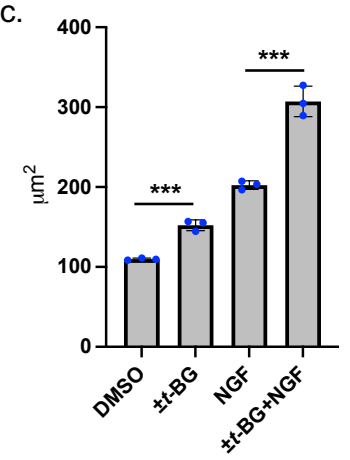

Figure 3. Effect of NGF and $\pm \boldsymbol{t}$-BG on PC 12 cell line a) Neuritogenesis cell assays in PC 12 cell line. PC 12 cells were cultured in DMEM containing 5\% FBS+5\% HS, after $24 \mathrm{~h}$ the media was changed to DMEM containing $2 \%$ HS $+1 \%$ FBS and cells were treated as follows: DMSO (control, $0.6 \%), \pm \boldsymbol{t}$-BG $(30 \mu \mathrm{M}+0.6 \%$
DMSO), NGF (10 ng/mL + 0.6\% DMSO), and $\pm \boldsymbol{t}$ - BG + NGF $(30 \mu \mathrm{M} \boldsymbol{t}$-BG $+10 \mathrm{ng} / \mathrm{mL} \mathrm{NGF}+0.6 \%$ DMSO). After $48 \mathrm{~h}$ of treatment, cells were fixed, stained with Hoescht stain (nuclei, blue) and labelled with anti- $\beta$-tubulin III antibody (cell body, green) for visualization and analysis on metaXpress HCA (10x). (b) \%Neuritogenesis post treatment was calculated as a percentage of total number of cells that had neurites $>5 \mu \mathrm{m}$. (c) Average cell body area measured for each treatment. p-value measured by unpaired t-test $* * * \mathrm{p}<0.001, * * \mathrm{p}<0.01$.

Though modest compared to NGF, synthetic trans-banglene caused statistically significant increases in PC 12 neuritogenesis, as shown in Figure $3 \mathrm{~b}$. Interestingly, the combined treatment of trans-banglene and NGF resulted in strongly augmented neuritogenesis levels, demonstrating a potentiating effect of trans-banglene. ${ }^{15}$ Average cell body area was also increased in relation to increased neuritogenesis levels (Figure $3 c)$. a.

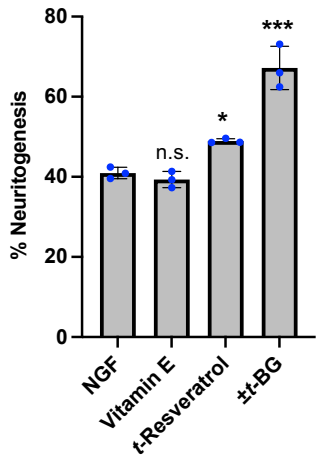

C.

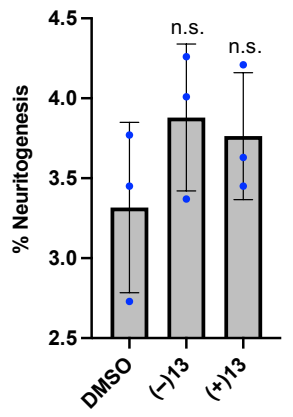

b.

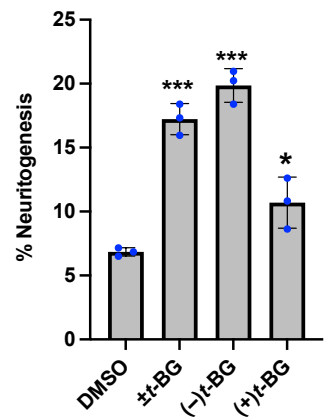

d.

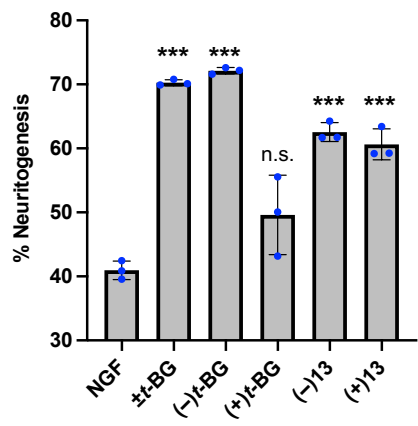

Figure 4. Quantification of neuritogenesis in PC 12 cell assays (a) Effect of common antioxidants when tested at $30 \mu \mathrm{M}$ in the presence of $10 \mathrm{ng} / \mathrm{mL}$ of NGF (b) Trend of neuritogenesis after treatment with $30 \mu \mathrm{M}$ of racemic $\pm \boldsymbol{t}$-BG or individual enantiomers: ( $-\boldsymbol{t}$-BG, (+) $\boldsymbol{t}$-BG (c) Neuritogenesis levels after treatment with $30 \mu \mathrm{M} \mathrm{Z}$ derivatives of $\boldsymbol{t}$-BG (-)13 and (+)13 (d) NGF neuritogenesis potentiation: all compounds were tested at $30 \mu \mathrm{M}$ in the presence of $10 \mathrm{ng} / \mathrm{mL}$ of NGF. \%Neuritogenesis post treatment was calculated as a percentage of total number of cells that had neurites $>5 \mu \mathrm{m}$. p-value measured by ANOVA followed by Dunnett's multiple comparison test vs. DMSO (b. and c.) and vs. NGF (a and $\mathrm{d}) * \mathrm{p}<0.05, * * * \mathrm{p}<0.001$.

Given the electron-rich aromatic rings in the banglene structure, banglenes could act as antioxidants. To establish whether the neuritogenesis effects observed were due to non-specific antioxidant activity, tocopherol acetate (acetylated vitamin E) and trans-resveratrol were both evaluated in the PC 12 neuritogenesis assay. These two antioxidants were chosen for their chemical similarity to banglenes: tocopherol acetate is lipophilic $(\log \mathrm{P}=10.9),{ }^{16}$ and trans-resveratrol has electron-rich styrenyl aromatic rings. 


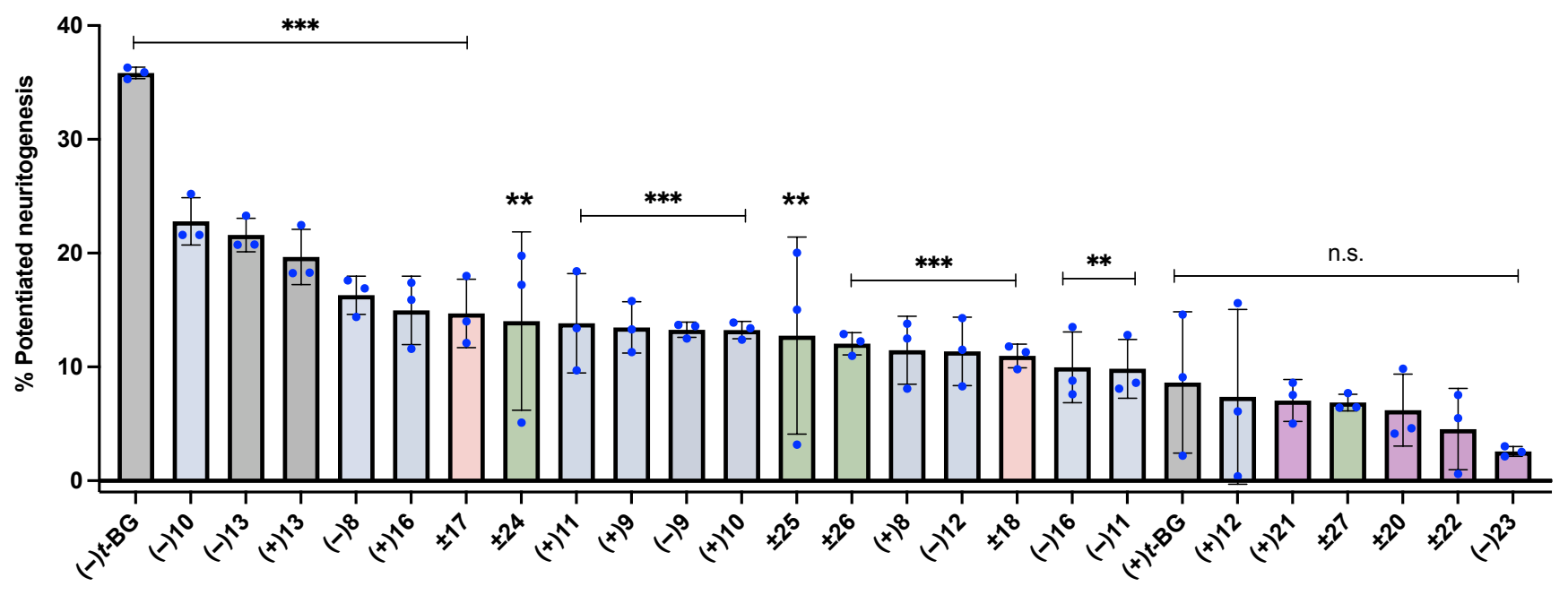

Figure 5. Neuritogenesis potentiated by analogues in the presence of NGF. All compounds were tested at $30 \mu \mathrm{M}$ along with $10 \mathrm{ng} / \mathrm{mL}$ of NGF and $0.6 \%$ DMSO. \%Neuritogenesis post treatment was calculated as a percentage of total number of cells that had neurites $>5 \mu \mathrm{m}$. $\%$ Potentiated neuritogenesis $=\%$ neuritogenesis $(30 \mu \mathrm{M}$ compound $+10 \mathrm{ng} / \mathrm{mL}$ NGF $)-\%$ neuritogenesis $(10 \mathrm{ng} / \mathrm{mL}$ NGF$)$. p-value measured by ANOVA followed by Dunnett's multiple comparison test vs. NGF $*_{p}<0.05, * * p<0.01, * * * p<0.001$. Colors reflect the location of $\boldsymbol{t}$-BG modification for each derivative tested. Blue $=\mathrm{A}$ ring; green $=\mathrm{B}$ ring; red $=\mathrm{C}$ ring; purple $=$ both $\mathrm{A}$ and $\mathrm{C}$ rings.

While trans-resveratrol treatment resulted in minor increases in neuritogenesis levels, neither antioxidant appeared to have similar levels of neurotrophic activity compared to transbanglene (Figure 4a).

All stereoisomers of trans-banglene were separately tested for activity, both alone and in combination with NGF treatment. (-) trans-banglene is observed to be the active enantiomer, with an NGF potentiation $\mathrm{EC}_{50}=14 \pm 1 \mu \mathrm{M}$, while $(+)$ trans-banglene causes minimal neurotrophic effects in these studies. Interestingly, $\mathrm{Z}$ alkene isomers of trans-banglene, $(+) \mathbf{1 3}$ and $(-) \mathbf{1 3}$, both exhibited potentiating effects in the presence of NGF but did not increase differentiation and neurite outgrowth when administered in the absence of NGF.

Collectively, these results show that the activity of transbanglene is structure dependent, increasing the likelihood of a specific recognition event in the PC 12 cell. Prior to this work, the enantiomers of trans-banglene had only been tested for P-glycoprotein (Pgp) antagonist activity. ${ }^{14}$

Synthetic derivatives of trans-banglene were then screened for NGF-potentiating activity (Figure 5). While (-) transbanglene elicited the largest neuritogenesis increases, many derivatives were identified with statistically significant potentiating effects. Modifications were tolerated on either the A or $\mathrm{C}$ rings, but modifications on both resulted in loss of activity. Changes to the substitution pattern of the A ring was particularly well tolerated, with all E-alkene isomer derivatives demonstrating potentiating activity. Compound 19, the only derivative with a hydroxyl group, positioned on the $\mathrm{C}$ ring, resulted in high levels of cell death.

Modification of the two alkenes of trans-banglene was also tolerated. Importantly, cis derivatives 25 and 27 were observed to be soluble in media at $30 \mu \mathrm{M}$ concentrations. The conformationally flexible hydrogenated derivatives $\mathbf{2 4}$ and $\mathbf{2 5}$ resulted in a decrease of potentiation effects by roughly half. Cyclopropanation of the $\mathrm{B}$ ring, which in contrast retains rigidity similar to that of an alkene, was tolerated for trans derivative $\mathbf{2 6}$ but also resulted in a similar decrease in potentiating effects.
Given these activity trends, we examined the most active derivative, $(-) \mathbf{1 0}$, its ring A analog 18, hydrogenated transderivative 24, and cyclopropyl ester derivative $\mathbf{2 6}$ for neuritogenesis effects in the absence of NGF. Interestingly, only compounds $\mathbf{2 4}$ and $\mathbf{2 6}$ demonstrated neurotrophic activity in this assay. Therefore, modifications to the substitution patterns on the $\mathrm{A}$ and $\mathrm{C}$ rings appear to abrogate neurotrophic activity, despite being tolerated for NGF potentiation responses. Further, the lack of neurotrophic activity of Z-alkene derivatives $(-) \mathbf{1 3}$ and $(+) \mathbf{1 3}$ also demonstrates that neurotrophic activity is sensitive to styrenyl alkene geometry.

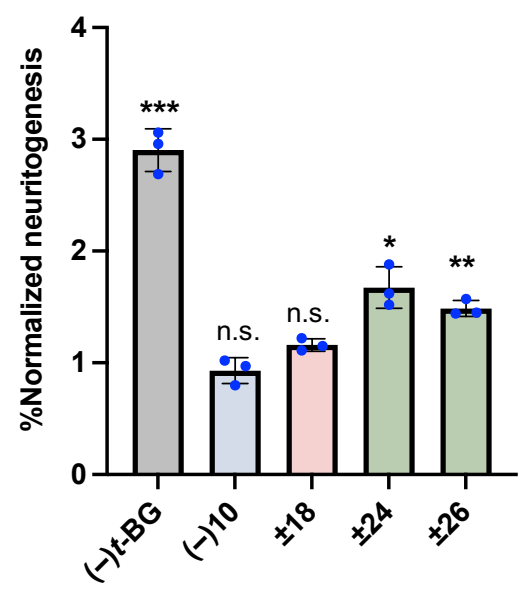

Figure 6. \%Normalized neuritogenesis after treatment with 30 $\mu \mathrm{M}$ derivatives of trans-Banglene for $48 \mathrm{~h}+0.6 \%$ DMSO. $\%$ Neuritogenesis was calculated as a percentage of total number of cells that had neurites $>5 \mu \mathrm{m}$. \%Normalized neuritogenesis was calculated as \%neuritogenesis (Compound) / \%neuritogenesis (DMSO), p-value measured by unpaired t-test, values compared to control (DMSO), ${ }^{*} \mathrm{p}<0.05,{ }^{* *} \mathrm{p}<0.01,{ }^{* * *} \mathrm{p}<0.001$

\section{Chemical Inhibitor Testing}

The potentiating effect of (-) trans-banglene suggests that it facilitates NGF-mediated signal transduction, either directly or 
by increasing the expression of cell machinery or transcription factors necessary for NGF-mediated neuritogenesis.

Canonical NGF neurotrophic signal transduction is initiated by the binding of NGF to tropomyosin receptor kinase A (TrkA, Figure 7a). TrkA undergoes autophosphorylation, which in turn initiates signal transduction through protein kinase $\mathrm{C}(\mathrm{Pkc})$, protein kinase $\mathrm{B}(\mathrm{Akt} / \mathrm{Pkb})$, and/or mitogen activated protein kinases (Raf, Mek, Erk). TrkA activation of these kinases is associated with neural plasticity, cell survival, and differentiation responses, respectively. ${ }^{17,18}$

To investigate the effect that trans-banglene has on TrkAinitiated signal transduction in each of these parallel pathways, NGF-induced neuritogenesis levels were measured in the presence of three chemical inhibitors, triciribine (iAkt), Gö 6983 (iPkc), and SCH772984 (iErk). Triciribine inhibits the phosphorylation, and subsequent activation, of Akt1/2/3. ${ }^{19}$ Triciribine binds to the Akt pleckstrin homology $(\mathrm{PH})$ domain and prevents the localization of Akt to the plasma membrane, which is required for phosphorylation and activation of Akt by Pdk1. Gö 6983 is a Pkc inhibitor, and acts as a competitive inhibitor of ATP binding. ${ }^{20}$ Gö 6983 has been shown to be pan-specific, inhibiting the $\alpha, \beta, \gamma$, and $\delta$ isoforms of Pkc. ${ }^{21}$ SCH772984 is also a competitive inhibitor of ATP binding, but for Erk1/2. Despite similar mechanisms, Gö 6983 and SCH772984 have demonstrated high specificity for their target kinases, with the latter having been tested on over 300 different kinases. $^{22}$

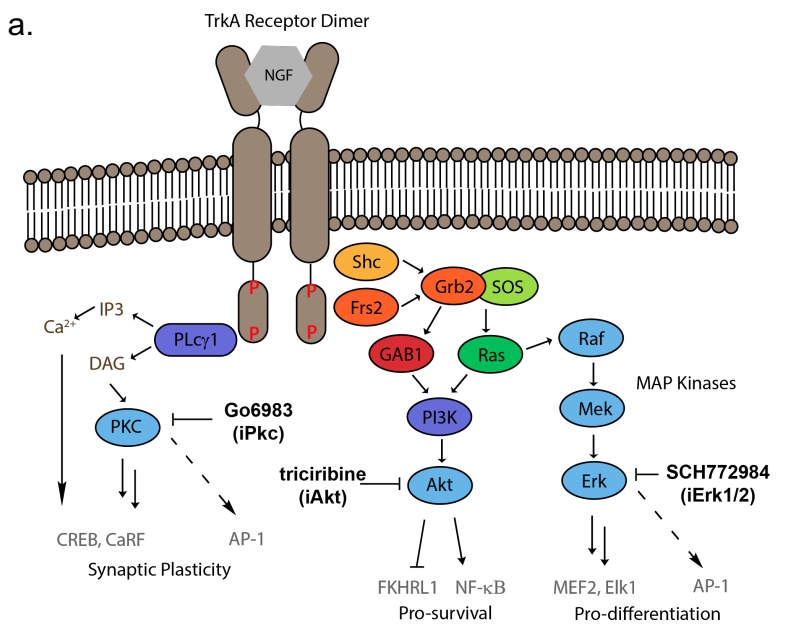

b.

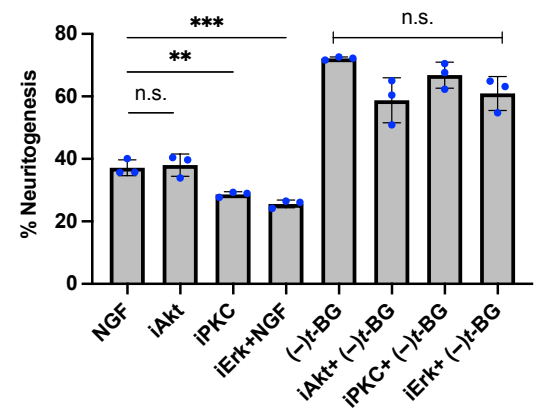

Figure 7. Investigation of (-) $\boldsymbol{t}$-BG's impact on neurotrophic signaling pathway (a) NGF-mediated signal transduction pathways with sites of inhibitor action. (b) Effect of pathway inhibi- tors on NGF $(10 \mathrm{ng} / \mathrm{mL}+0.6 \% \mathrm{DMSO})$ and $(-) \boldsymbol{t}$-BG $(30 \mu \mathrm{M}+$ $10 \mathrm{ng} / \mathrm{mL} \mathrm{NGF}+0.6 \% \mathrm{DMSO})$ signaling. $\mathrm{p}$-value measured by ANOVA followed by Dunnett's multiple comparison test $* * \mathrm{p}<0.01, * * * \mathrm{p}<0.001$

Inhibition of Pkc and Erk activity by Gö 6983 (iPkc) and SCH772984 (iErk) resulted in a significant decrease in NGFinduced neuritogenesis observed in PC 12 cells. However, inhibition of Akt activity by triciribine treatment (iAkt) did not result in a similar decrease in neuritogenesis levels. This is consistent with NGF-mediated Akt activation being associated with cell survival. Cell survival phenotypes are often independent of neuritogenesis responses. ${ }^{17}$ In contrast, Pkc and Erk activation is associated with neural plasticity and differentiation, which directly relate to neurite outgrowth. ${ }^{18}$

Interestingly, (-) trans-banglene treatment rescued NGFinduced neuritogenesis levels in the presence of these inhibitors and further resulted in potentiated neuritogenesis that was statistically similar to levels observed in the absence of the inhibitors. These response data indicate that the potentiating activity of $(-)$ trans-banglene is not expressly reliant on $\mathrm{Pkc}$ or Erk activity.

\section{CONCLUSIONS}

Structure dependency for activity is a hallmark of a discrete cellular target. Only one enantiomer of trans-banglene demonstrated both neurotrophic activity and strong potentiating activity. However, structure-activity studies also revealed that the degree of potentiating activity for banglene derivatives is not proportional to neurotrophic activity in the absence of NGF. This lack of correlation becomes clear when comparing derivatives 10, 13, 18, 24, and 26. Such differences in structure-activity response constitute evidence of dual-function, and further, may be the result of a dual-mechanism for (-) transbanglene action.

An important consideration in exploring the mechanism of (-) trans-banglene activity is whether TrkA is a likely target for (-) trans-banglene recognition. Other small molecules have been identified that modulate TrkA activity, whether in the presence or absence of NGF protein., 23-27 Gambogic amide is known to activate TrkA autophosphorylation and subsequent signal transduction, ${ }^{28}$ while sarcodonin $G$ potentiates NGF activity by increasing TrkA's binding affinity for NGF ${ }^{29}$ If (-) trans-banglene was able to both activate TrkA and modulate TrkA binding affinity to NGF, then structural changes that improve NGF potentiation might not correlate with improvements in direct TrkA activation, consistent with observed differences in structure-activity relationship studies in the presence and absence of NGF protein.

However, the lack of sensitivity of (-) trans-banglene potentiating effects to pan-Pkc and Erk1/2 inhibitors, which should dampen the effects of TrkA signal transduction, is inconsistent with TrkA as a cellular target of (-) trans-banglene. Pkc and Mek inhibitors strongly suppress the potentiation of NGF activity by sarcodonin G, for example. ${ }^{29}$

Similarly, if potentiation effects are the result of increased cellular production of NGF (or proNGF), such potentiating effects should also be sensitive to chemical inhibitors of Pkc and Erk proteins. These results suggest that (-) trans-banglene either activates neuritogenic signaling responses that are 
downstream of Pkc and Erk, or that are independent of canonical NGF signal transduction pathways.

While the exact details of the mechanism of (-) transbanglene remain unclear, this work has established the design principles for mechanistic probe development and demonstrates that there are two different modes in which (-) transbanglene can act on a cell - in the absence or presence of NGF protein. Further, traditional TrkA/NGF activated kinases are not central to NGF-dependent (-) trans-banglene action.

Of particular promise is the discovery in this work that cyclopropyl ester 26 exhibits both neurotrophic and NGFpotentiating activity. The ester of $\mathbf{2 6}$ is primed for the conjugation of mechanistic reporters or cross-linking functionality that can facilitate cellular target identification. Such studies constitute immediate future work to further the annotation of $(-)$ trans-banglene's mechanism of action.

\section{Significance}

One of the unique challenges to the study of the brain is the limited permeability of the blood brain barrier (BBB) to many active agents. This challenge hinders our ability to modulate certain cellular responses in a functioning brain. Neurotrophin signaling, in particular, is central to neuron survival and function, and is naturally antithetical to neurodegenerative progression. ${ }^{18}$ Unfortunately, instability and a lack of BBB permeability reduces neurotrophin use in the study of neurodegenerative animal models and prevents its use in the treatment of neurodegenerative diseases. The neurotrophic signal transduction initiated by neurotrophins is complex, and therefore demands precise chemical and biochemical tools to facilitate its study and deepen our understanding. This work provides the foundational knowledge necessary for mechanistic models that will allow for identification of the mechanisms of action for $(-)$ trans-banglene and provides further information on its mode of action. Importantly, (-) trans-banglene is easily accessed synthetically (2-3 steps). Combined with known and favorable pharmacokinetic properties, once the mechanism of action is identified, this molecule will be an important chemical tool to modulate neurotrophic responses and to understand their role in both normal brain function and in many disease settings.

\section{ASSOCIATED CONTENT}

\section{Supporting Information}

Supporting information document A includes synthetic protocols, characterization data for all compounds (including purity and enantio-enrichment data), HPLC traces, PC 12 cell assay protocols and dose response study of $(-) t$-BG.

Supporting information document B includes NMR spectra

\section{AUTHOR INFORMATION}

\section{Corresponding Author}

* Prof. Florence J. Williams

Department of Chemistry

University of Iowa

Iowa City, Iowa, 52242 (USA)

E-mail: florence-williams@uiowa.edu

\section{Author Contributions}

KG performed synthesis of 8-18 and 20-23 compounds as well as all cell culture and biological testing. MZK performed the synthesis of 19 and 24-27.

The manuscript was written by KG and FJW. / All authors have given approval to the final version of the manuscript.

\section{Funding Sources}

This work was supported by the Canada Research Coordinating Committee NFRFE-2018-00223, the Canadian Foundation for Innovation IOF-34997, the University of Alberta and the University of Iowa.

\section{ACKNOWLEDGMENT}

The authors would like to thank Gareth Lambkin for advice and maintenance of shared cell culture facilities. We would also like to thank Prof. Robert Campbell and the Campbell lab for the donation of select cell culture consumables, as well as Lotus Separations for separating the enantiomers of $t$-BG and the PhenoLogix applications team at Phenomenex for developing the chiral HPLC method for separating enantiomers of banglene derivatives.

\section{ABBREVIATIONS}

NGF, nerve growth factor; $A \beta$, amyloid Beta; $B B B$, blood-brain barrier; HCA, high content analyser; Trk A, tropomyosin receptor kinase $\mathrm{A}$; $\mathrm{Pkc}$, protein kinase $\mathrm{C}, \mathrm{Pkb}$, protein kinase

\section{REFERENCES}

1. Dugger, B. N.; Dickson, D. W., Pathology of Neurodegenerative Diseases. Cold Spring Harb. Perspect. Biol. 2017, 9 (7), a028035.

2. Cummings, J. L.; Morstorf, T.; Zhong, K. J. A. s. R.; Therapy, Alzheimer's disease drug-development pipeline: few candidates, frequent failures. Alzheimer's Res. Ther. 2014, 6 (4), 37.

3. Reichardt, L. F., Neurotrophin-regulated signalling pathways. Philos. Trans. R. Soc. Lond.: Biol. Sci. 2006, 361 (1473), 15451564.

4. Xu, J.; Lacoske, M. H.; Theodorakis, E. A., Neurotrophic natural products: chemistry and biology. Angew. Chem. Int. Ed. Engl. 2014, 53 (4), 956-87.

5. $\quad \mathrm{Su}, \mathrm{R} . ; \mathrm{Su}, \mathrm{W}$.; Jiao, Q., NGF protects neuroblastoma cells against $\beta$-amyloid-induced apoptosis via the $\mathrm{Nrf} 2 / \mathrm{HO}-1$ pathway. FEBS Open Bio. 2019, 9 (12), 2063-2071.

6. Jiao, S. S.; Shen, L. L.; Zhu, C.; Bu, X. L.; Liu, Y. H.; Liu, C. H.; Yao, X. Q.; Zhang, L. L.; Zhou, H. D.; Walker, D. G.; Tan, J.; Gotz, J.; Zhou, X. F.; Wang, Y. J., Brain-derived neurotrophic factor protects against tau-related neurodegeneration of Alzheimer/'s disease. Trans. Psychiatry 2016, 6, e907.

7. Zigova, T.; Pencea, V.; Wiegand, S. J.; Luskin, M. B., Intraventricular Administration of BDNF Increases the Number of Newly Generated Neurons in the Adult Olfactory Bulb. Mol. Cell. Neurosci. 1998, 11 (4), 234-245.

8. Nagahara, A. H.; Merrill, D. A.; Coppola, G.; Tsukada, S.; Schroeder, B. E.; Shaked, G. M.; Wang, L.; Blesch, A.; Kim, A.; Conner, J. M.; Rockenstein, E.; Chao, M. V.; Koo, E. H.; Geschwind, D.; Masliah, E.; Chiba, A. A.; Tuszynski, M. H., Neuroprotective effects of brain-derived neurotrophic factor in rodent and primate models of Alzheimer's disease. Nat. Med. 2009, 15 (3), 331-337.

9. Pan, W.; Banks, W. A.; Kastin, A. J., Permeability of the blood-brain barrier to neurotrophins. Brain Res. 1998, 788.

10. Tong, Q.; Wang, F.; Zhou, H. Z.; Sun, H. L.; Song, H.; Shu, Y. Y.; Gong, Y.; Zhang, W. T.; Cai, T. X.; Yang, F. Q.; Tang, J.; Jiang, T., Structural and functional insights into lipid-bound nerve growth factors. Faseb j 2012, 26 (9), 3811-21.

11. Tuntiwachwuttikul, P.; Limchawfar, B.; Reutrakul, V.; Kusamran, K.; Byrne, L., Syntheses of some constituents of Zingiber cassumunar. Aust. J. Chem. 1980, 33 (4), 913-916. 
12. Matsui, N.; Kido, Y.; Okada, H.; Kubo, M.; Nakai, M.; Fukuishi, N.; Fukuyama, Y.; Akagi, M., Phenylbutenoid dimers isolated from Zingiber purpureum exert neurotrophic effects on cultured neurons and enhance hippocampal neurogenesis in olfactory bulbectomized mice. Neurosci. Lett. 2012, 513 (1), 72-7.

13. Kato, E.; Kubo, M.; Okamoto, Y.; Matsunaga, Y.; Kyo, H.; Suzuki, N.; Uebaba, K.; Fukuyama, Y., Safety Assessment of Bangle (Zingiber purpureum Rosc.) Rhizome Extract: Acute and Chronic Studies in Rats and Clinical Studies in Human. ACS Omega 2018, 3 (11), 15879-15889.

14. Chu, J.; Suh, D. H.; Lee, G.; Han, A. R.; Chae, S. W.; Lee, H. J.; Seo, E. K.; Lim, H. J., Synthesis and biological activity of optically active phenylbutenoid dimers. J. Nat. Prod. 2011, 74 (8), 1817 21.

15. Yanagimoto, T.; Kishimoto, S.; Kasai, Y.; Matsui, N.; Kubo, M.; Yamamoto, H.; Fukuyama, Y.; Imagawa, H., Design and synthesis of dual active neovibsanin derivatives based on a chemical structure merging method. Bioorg. Med. Chem. Lett. 2020, 30 (20), 127497.

16. Pubchem compound summary for CID 1742129, (-)-alphaTocopherol. NLM: NCBI, 2021.

17. Rai, S. N.; Dilnashin, H.; Birla, H.; Singh, S. S.; Zahra, W.; Rathore, A. S.; Singh, B. K.; Singh, S. P., The Role of PI3K/Akt and ERK in Neurodegenerative Disorders. Neurotox. Res. 2019, 35 (3), 775-795.

18. Thiele, C. J.; Li, Z.; McKee, A. E., On Trk -- The TrkB Signal Transduction Pathway Is an Increasingly Important Target in Cancer Biology. Clin. Cancer Res. 2009, 15 (19), 5962-5967.

19. Berndt, N.; Yang, H.; Trinczek, B.; Betzi, S.; Zhang, Z.; Wu, B.; Lawrence, N. J.; Pellecchia, M.; Schönbrunn, E.; Cheng, J. Q.; Sebti, S. M., The Akt activation inhibitor TCN-P inhibits Akt phosphorylation by binding to the $\mathrm{PH}$ domain of Akt and blocking its recruitment to the plasma membrane. Cell. Death Differ. 2010, 17 (11), 1795-1804.

20. Toullec, D.; Pianetti, P.; Coste, H.; Bellevergue, P.; GrandPerret, T.; Ajakane, M.; Baudet, V.; Boissin, P.; Boursier, E.; Loriolle, F., The bisindolylmaleimide GF $109203 \mathrm{X}$ is a potent and selective inhibitor of protein kinase C. J. Biol. Chem. 1991, 266 (24), 15771-15781.

21. Gschwendt, M.; Fürstenberger, G.; Leibersperger, H.; Kittstein, W.; Lindner, D.; Rudolph, C.; Barth, H.; Kleinschroth, J.; Marmé, D.; Schächtele, C.; Marks, F., Lack of an effect of novel inhibitors with high specificity for protein kinase $\mathrm{C}$ on the action of the phorbol ester 12-O-tetradecanoylphorbol-13-acetate on mouse skin in vivo. Carcinogenesis 1995, 16 (1), 107-111.

22. Morris, E. J.; Jha, S.; Restaino, C. R.; Dayananth, P.; Zhu, H.; Cooper, A.; Carr, D.; Deng, Y.; Jin, W.; Black, S.; Long, B.; Liu, J.; DiNunzio, E.; Windsor, W.; Zhang, R.; Zhao, S.; Angagaw, M. H.; Pinheiro, E. M.; Desai, J.; Xiao, L.; Shipps, G.; Hruza, A.; Wang, J.; Kelly, J.; Paliwal, S.; Gao, X.; Babu, B. S.; Zhu, L.; Daublain, P.; Zhang, L.; Lutterbach, B. A.; Pelletier, M. R.; Philippar, U.; Siliphaivanh, P.; Witter, D.; Kirschmeier, P.; Bishop, W. R.; Hicklin, D.; Gilliland, D. G.; Jayaraman, L.; Zawel, L.; Fawell, S.; Samatar, A. A., Discovery of a Novel ERK Inhibitor with Activity in Models of Acquired Resistance to BRAF and MEK Inhibitors. Cancer Discov. 2013, 3 (7), 742-750.

23. Longo, F. M.; Massa, S. M., Small-molecule modulation of neurotrophin receptors: a strategy for the treatment of neurological disease. Nat. Rev. Drug. Discov. 2013, 12 (7), 507-525.

24. Lazaridis, I.; Charalampopoulos, I.; Alexaki, V.-I.; Avlonitis, N.; Pediaditakis, I.; Efstathopoulos, P.; Calogeropoulou, T.; Castanas, E.; Gravanis, A., Neurosteroid Dehydroepiandrosterone Interacts with Nerve Growth Factor (NGF) Receptors, Preventing Neuronal Apoptosis. PLoS Biol. 2011, 9 (4), e1001051.

25. Dahlström, M.; Madjid, N.; Nordvall, G.; Halldin, M. M.; Vazquez-Juarez, E.; Lindskog, M.; Sandin, J.; Winblad, B.; Eriksdotter, M.; Forsell, P., Identification of Novel Positive Allosteric
Modulators of Neurotrophin Receptors for the Treatment of Cognitive Dysfunction. Cells 2021, 10 (8), 1871.

26. Saragovi, H. U.; Galan, A.; Levin, L. A., Neuroprotection: Pro-survival and Anti-neurotoxic Mechanisms as Therapeutic Strategies in Neurodegeneration. Front. Cell. Neurosci. 2019, 13 (231).

27. Scarpi, D.; Cirelli, D.; Matrone, C.; Castronovo, G.; Rosini, P.; Occhiato, E. G.; Romano, F.; Bartali, L.; Clemente, A. M.; Bottegoni, G.; Cavalli, A.; De Chiara, G.; Bonini, P.; Calissano, P.; Palamara, A. T.; Garaci, E.; Torcia, M. G.; Guarna, A.; Cozzolino, F., Low molecular weight, non-peptidic agonists of TrkA receptor with NGF-mimetic activity. Cell Death Dis. 2012, 3 (7), e339-e339.

28. Jang, S.-W.; Okada, M.; Sayeed, I.; Xiao, G.; Stein, D.; Jin, P.; Ye, K., Gambogic amide, a selective agonist for TrkA receptor that possesses robust neurotrophic activity, prevents neuronal cell death. Proc. Nat. Acad. Sci. 2007, 104 (41), 16329-16334.

29. Cao, C.-Y.; Zhang, C.-C.; Shi, X.-W.; Li, D.; Cao, W.; Yin, X.; Gao, J.-M., Sarcodonin G Derivatives Exhibit Distinctive Effects on Neurite Outgrowth by Modulating NGF Signaling in PC12 Cells. ACS Chem. Neurosci. 2018, 9 (7), 1607-1615. 